\title{
Unveiling the role of Gardnerella vaginalis in polymicrobial Bacterial Vaginosis biofilms: the impact of other vaginal pathogens living as neighbors
}

\author{
Joana Castro $^{1,2} \cdot$ Daniela Machado $^{1} \cdot$ Nuno Cerca $\mathbb{D}^{1}$
}

Received: 26 April 2018 / Revised: 13 September 2018 / Accepted: 3 December 2018 / Published online: 22 January 2019

(c) International Society for Microbial Ecology 2019. This article is published with open access

\begin{abstract}
Bacterial vaginosis (BV) is characterized by a highly structured polymicrobial biofilm, which is strongly adhered to the vaginal epithelium and primarily consists of the bacterium Gardnerella vaginalis. However, despite the presence of other $\mathrm{BV}$-associated bacteria, little is known regarding the impact of other species on BV development. To gain insight into BV progress, we analyzed the ecological interactions between $G$. vaginalis and $15 \mathrm{BV}$-associated microorganisms using a dualspecies biofilm model. Bacterial populations were quantified using a validated peptide nucleic acid fluorescence in situ hybridization approach. Furthermore, biofilm structure was analyzed by confocal laser scanning microscopy. In addition, bacterial coaggregation ability was determined as well as the expression of key virulence genes. Remarkably, our results revealed distinct biofilm structures between each bacterial consortium, leading to at least three unique dual-species biofilm morphotypes. Furthermore, our transcriptomic findings seem to indicate that Enterococcus faecalis and Actinomyces neuii had a higher impact on the enhancement of $G$. vaginalis virulence, while the other tested species had a lower or no impact on $G$. vaginalis virulence. This study casts a new light on how BV-associated species can modulate the virulence aspects of G. vaginalis, contributing to a better understanding of the development of BV-associated biofilms.
\end{abstract}

\section{Introduction}

Bacterial vaginosis (BV) is the most common vaginal infection in women of reproductive age worldwide [1]. It is associated with adverse outcomes relating to both pregnancy [2] and fertility [3]. BV is characterized by a dramatic shift in the vaginal microbiota population, which involves the loss of beneficial bacteria (normally Lactobacillus-dominated) and a simultaneous proliferation of a complex mixture of other microorganisms [4-8]. The

Supplementary information The online version of this article (https:// doi.org/10.1038/s41396-018-0337-0) contains supplementary material, which is available to authorized users.

Nuno Cerca

nunocerca@ceb.uminho.pt

1 Centre of Biological Engineering (CEB), Laboratory of Research in Biofilms Rosário Oliveira (LIBRO), University of Minho, Campus de Gualtar, 4710-057 Braga, Portugal

2 Instituto de Ciências Biomédicas Abel Salazar (ICBAS), University of Porto, Rua de Jorge Viterbo Ferreira 228, 4050-313 Porto, Portugal specific roles of the multiple microorganisms associated with BV, such as Atopobium vaginae, Prevotella bivia, Mobiluncus mulieris, Corynebacterium amycolatum, Fusobacterium nucleatum, Dialister, Enterococcus faecalis, Eggerthella, Leptotrichia, Megasphaera, and Ureaplasma urealyticum, are largely unknown [9-11] with Gardnerella vaginalis currently the best-studied species [5, 12-15]. The role of G. vaginalis in BV is not without controversy, however. First proposed as the sole etiological agent by Gardner and Dukes [16] and later studied by cultivation-independent approaches [17-19], its presence in healthy women cast doubt on its virulence potential $[13,20]$. Nevertheless, in the past decade, it has been demonstrated that $G$. vaginalis had a significantly higher virulence potential than many other BV-associated species, as defined by higher initial adhesion and cytotoxic effect, as well as a greater propensity to form a biofilm [21-23]. Furthermore, recent genomic analysis revealed four $G$. vaginalis genome groups, with great differences between each other [19, 24-26]. Herein, we will refer to $\mathrm{BV}$-associated G. vaginalis (BVGv) as isolates from women with $\mathrm{BV}$ that were previously phenotypically characterized as virulent isolates [13]. 
Due to its strong adherence to vaginal cells and biofilmforming capacities, it has been suggested that BVGv initiates the colonization of the vaginal epithelium and serves as a scaffold to which other species subsequently can attach [11, 27-29]. As a result, during BV, there is a complex interplay between pathogenic species, endogenous vaginal microbiota, and the vaginal epithelium $[5,30]$. Due to the presumably central role of $\mathrm{BVGv}$ in $\mathrm{BV}$ development, it is crucial to assess how secondary BV-associated microbial species interact with BVGv. The study of these microbial interactions is extremely important for obtaining knowledge of the pathogenicity of microbes in the host and for the development of effective treatments without relapses, a common problem in BV $[31,32]$. Some studies have already evaluated the interplay between $G$. vaginalis and other BV-associated species in biofilms [33-36]. However, all these studies were carried out by observing a few phenotypic aspects of the interactions between $G$. vaginalis and $\mathrm{BV}$-associated species, and, as such, more detailed studies are needed.

We recently showed that $G$. vaginalis exhibits a specific gene expression behavior according to its phenotype form, probably to overcome the host defenses and allow the colonization of mucosal tissue [37]. However, hardly any information exists on how BVGv gene expression is influenced by the presence of other BV-associated bacteria. It has been previously shown that co-culturing dual-species biofilms involves very specific alterations in gene expression, as observed in the oral biofilms microbiome [38], between staphylococcal species [39] and in Veillonella parvula and Streptococcus mutans consortia [40]. Therefore, we hypothesize that molecular interactions between $G$. vaginalis and multiple $\mathrm{BV}$-associated bacteria could be very specific, highlighting possible key roles in BV development by some secondary anaerobes. Thus, in an effort to better understand the virulence of BVGv in polymicrobial communities, the aim of the present study was to analyze the interactions between Actinomyces neuii, Atopobium vaginae, Brevibacterium ravenspurgense, Corynebacterium amycolatum, Corynebacterium tuscaniense, Enterococcus faecalis, Mobiluncus mulieris, Nosocomicoccus ampullae, Prevotella bivia, Propionibacterium acnes, Staphylococcus hominis, Staphylococcus saprohyticus, Staphylococcus simulans, Staphylococcus warnerii, Streptococcus anginosus, and BVGv using a dual-species biofilm assembly.

\section{Methods}

\section{Bacterial strains and culture conditions}

G. vaginalis strain UM241 was isolated from a woman diagnosed with BV [13]. Fifteen more bacterial species associated with BV were included in this study, namely: $A$. neuii, A. vaginae, $B$. ravenspurgense, $C$. amycolatum, $C$. tuscaniense, E. faecalis, N. ampullae, P. acnes, S. hominis, $S$. saprohyticus, S. simulans, S. warnerii, S. anginosus, $M$. mulieris, and P.bivia. More details on the species used here are found in Supplementary Table S1. The selection of these species was based on their feasibility to growth in vitro and the existence of previous phenotypic evidence of some key characteristics, including adhesion to HeLa cells, biofilm formation, cytotoxic assays as well as the determination of antimicrobial tolerance [22, 23, 41, 42]. Each inoculum was grown in sBHI [Brain-heart infusion (Liofilchem, Rosetodegli Abruzzi, Italy) supplemented with $2 \%(\mathrm{wt} / \mathrm{wt})$ gelatin (Liofilchem), $0.5 \%(\mathrm{wt} / \mathrm{wt}$ ) yeast extract (Liofilchem), and $0.1 \%$ (wt/wt) soluble starch (Panreac, Barcelona, Spain)] for $24 \mathrm{~h}$ at $37^{\circ} \mathrm{C}$ with $10 \% \mathrm{CO}_{2}$ (Shel Lab, Cornelius, Oregon, USA) [23]. The exceptions were with consortia with the strict anaerobes A. vaginae, M. mulieris, and P. bivia [43], which were grown in sBHI and incubated at $37^{\circ} \mathrm{C}$, under strict anaerobic conditions (AnaeroGen Atmosphere Generation system; Oxoid, United Kingdom).

\section{Coaggregation assays}

To determine the extent of the coaggregation between $G$. vaginalis and $\mathrm{BV}$-associated bacteria we used an experimental model developed by Reid et al. [44]. In brief, $500 \mu \mathrm{L}$ of $G$. vaginalis $\left(10^{7} \mathrm{CFU} / \mathrm{mL}\right)$ was combined with $500 \mu \mathrm{L}$ of each BV-associated species $\left(10^{7} \mathrm{CFU} / \mathrm{mL}\right)$ in 24-well plates (Thermo Fisher Scientific, Lenexa, KS, USA). Then, bacteria were incubated for $4 \mathrm{~h}$, at $37^{\circ} \mathrm{C}$, in $10 \% \mathrm{CO}_{2}$. The aggregates were visualized using an inverted light microscope Leica DMI 3000B (Leica Microsystems GmbH, Wetzlar, Germany) and the score was evaluated as following: 0 , no aggregation; 1 , small aggregates comprising small visible clusters of bacteria; 2 , aggregates comprising larger numbers of bacteria, settling to the center of the well; 3 , macroscopically visible clumps comprising larger groups of bacteria which settle to the center of the well; 4, maximum score allocated to describe a large, macroscopically visible clump in the center of the well. Auto-aggregation was assessed for each bacterial strain. All assays were performed in duplicate and repeated in three different days.

\section{Biofilm formation}

Dual-species biofilms were formed using an in vitro model previously developed [21], in support of the hypothesis that $G$. vaginalis is the early colonizer in $\mathrm{BV}$, serving as a scaffold for other bacterial species incorporation [45]. Briefly, the cell concentration of $G$. vaginalis was assessed by optical density (OD) at $600 \mathrm{~nm}$ and this initial culture was further diluted in order to obtain a final concentration of 
approx. $10^{7} \mathrm{CFU} / \mathrm{mL}\left(\mathrm{OD}_{600} \mathrm{~nm}=0.15\right)$. After homogenization, $500 \mu \mathrm{L}$ of $G$. vaginalis suspensions were dispensed into each well of a 24-well flat-bottom tissue culture plate (Orange Scientific, Braine L'Alleud, Belgium). The tissue cultured plates were then placed in an incubator at $37{ }^{\circ} \mathrm{C}$ in $10 \% \mathrm{CO}_{2}$. Following $24 \mathrm{~h}$ of biofilm formation, the planktonic cells were removed carefully and $500 \mu \mathrm{L}$ of fresh medium was added to each well. At the same time, the suspension of second $\mathrm{BV}$-isolate was added (in a concentration approx. $10^{7}$ or $10^{5} \mathrm{CFU} / \mathrm{mL}$; Supplementary Table S1) to each well and the plates were further incubated for $24 \mathrm{~h}$. Then, the dual-species biofilms were washed once with phosphate buffer saline (PBS) solution. The 24 or $48 \mathrm{~h}$ mono-species biofilm of G. vaginalis was used as a control. sBHI was used as a negative control in all experiments to exclude any possible contamination. All assays were repeated three times with four technical replicates.

\section{PNA FISH hybridization and DAPI staining}

To quantify the total cells of mono- and dual-species biofilms, we used the method suggested by Freitas et al. [46]. In brief, biofilms were scraped and resuspended in PBS. The total cells of the mono- or dual-species biofilms were quantified using a Neubauer chamber coupled with an Olympus BX51 epifluorescence microscope equipped with a CCD camera (DP72; Olympus, Lisboa, Portugal). Cell suspensions were stained with 4'-6-diamidino-2-phenylindole (DAPI, $2.5 \mu \mathrm{g} / \mathrm{mL}$ ). DAPI staining was detected in a specific filter, BP 365-370, FT 400, LP 421 present in the microscope. Next, we discriminated the bacterial population of biofilm by using the peptide nucleic acid fluorescence in situ hybridization (PNA FISH) method as previously described [47]. Briefly, after fixing the biofilm suspension, a PNA probe specific for G. vaginalis (Gard162) was added to each well of epoxy-coated microscope glass slides (Thermo Fisher Scientific). An additional staining step was done at the end of the hybridization procedure, covering each glass slide with DAPI. Microscopic visualization was performed using filters capable of detecting the PNA probe (BP 530-550, FT 570, LP 591 sensitive to the Alexa Fluor 594 molecule attached to the Gard162 probe) and DAPI (as described above). An external control was performed to determine the sensitivity of the PNA probe for several dilutions of $48 \mathrm{~h} \mathrm{G}$. vaginalis mono-species biofilm cells, correlating the DAPI with PNA FISH counts.

\section{Confocal laser scanning microscopy analysis of biofilm bacterial distribution}

To analyze the bacterial distribution of dual-species biofilms, the biofilm structure was evaluated by confocal laser scanning microscopy (CLSM) using the PNA Gard162 probe coupled to DAPI staining as we described above. For this experiment, biofilms were formed on an eight-well chamber slide (Thermo Fisher Scientific ${ }^{\mathrm{TM}} \mathrm{Nunc}^{\mathrm{TM}} \mathrm{Lab}$ $\mathrm{Tek}^{\mathrm{TM}}$, Rochester, NY, USA) at $37{ }^{\circ} \mathrm{C}$ in $10 \% \mathrm{CO}_{2}$ for $48 \mathrm{~h}$ with replacement of sBHI medium at $24 \mathrm{~h}$ of growth and the addition of the respective second $\mathrm{BV}$-associated bacteria. The CLSM images were acquired in an Olympus ${ }^{\mathrm{TM}}$ FluoView FV1000 (Olympus) confocal scanning laser microscope, using a $\times 40$ objective. Images were acquired with $512 \times 512$ resolutions at four different regions of each surface analyzed.

\section{Gene expression quantification}

Dual-species biofilms were grown as described above. Gene expression of six potential virulence genes, namely vaginolysin (vly), sialidase (sld), HMPREF0424_0821, HMPREF0424_1122, HMPREF0424_0156, and HMPREF0424_1196, was determined according to our previous study [37]. For each tested condition, total RNA from a biofilm pooling (10 wells of a 24-well-plate) was extracted using an ExtractME RNA Bacteria \& Yeast kit (Blirt S.A., Poland) with minor changes, as optimized before [48]. Next, genomic DNA was degraded with one step of DNase treatment (Fermentas, Lithuania) following the manufacturer's instructions. RNA concentration, purity, and integrity were determined as described before [49]. The same amount of total RNA ( $300 \mathrm{ng} / \mu \mathrm{L})$ was reverse transcribed using the RevertAid ${ }^{\mathrm{TM}}$ First Strand cDNA synthesis kit (Fermentas), as previously optimized, and gene-specific reverse transcription primers as a priming strategy. Quantitative PCR (qPCR) was prepared by mixing together $5 \mu \mathrm{L}$ of $\mathrm{iQ}$ SYBR green supermix (Bio-Rad, Hercules, CA, USA), $2 \mu \mathrm{L}$ of 1:100 diluted cDNA, $0.5 \mu \mathrm{L}$ of $5 \mu \mathrm{M}$ Forward and Reverse primes and water up to $10 \mu \mathrm{L}$. The run was performed in a $\mathrm{CFX} 96^{\mathrm{TM}}$ thermal cycler (Bio-Rad) with the following cycling parameters: $3 \mathrm{~min}$ at $95^{\circ} \mathrm{C}$, followed by 45 cycles of $10 \mathrm{~s}$ at $95{ }^{\circ} \mathrm{C}, 10 \mathrm{~s}$ at $60^{\circ} \mathrm{C}$, and $15 \mathrm{~s}$ at $72^{\circ} \mathrm{C}$. Reaction efficiency was determined by the dilution method [50]. At $60{ }^{\circ} \mathrm{C}$ all set of primers (Supplementary Table S2) used had the highest and more similar efficiencies. Furthermore, the analysis of the obtained melting curves confirmed the presence of a single peak, demonstrating the specificity of the tested primers. Normalized gene expression was determined by using the delta $C_{\mathrm{t}}$ method $\left(E^{\Delta C t}\right)$, a variation of the Livak method, where $\Delta C_{\mathrm{t}}=C_{\mathrm{t}}$ (reference gene) $-C_{\mathrm{t}}$ (target gene) and $E$ stands for the reaction efficiency experimentally determined. A non-reverse transcriptase control was included in each reaction. At least three biologic replicates of each condition were performed with three technical replicates. 


\section{Statistical analysis}

All numerical data were subjected to statistical analysis using the independent samples $t$-test, paired sample $t$-test, or non-parametric Mann-Whitney $U$ test for the data that did not follow a normal distribution according Kolmogorov-Smirvon's test, with the statistical software package SPSS 17.0 (SPSS Inc. Chicago, IL). Results are presented as mean \pm standard deviation (s.d.) or as mean \pm standard error of mean (s.e.m.), unless stated otherwise.

\section{Results}

\section{Co-aggregation between G. vaginalis and other BV- associated isolates}

It has been described that coaggregation is highly specific and considered a virulence factor, since microbial aggregates are a common mechanism for the survival of bacteria in nature [51, 52]. Thus, our first aim was to analyze whether BVGv and other BV-associated bacteria could co-aggregate. As shown in Fig. 1, our data demonstrated that the distinct $\mathrm{BV}$-associated species coaggregate with BVGv in different degrees. Interestingly, A. vaginae, C. tuscaniense, $M$. mulieres, $P$. bivia, and $S$. anginosus were the bacterial species that caused the most pronounced effect in increasing microbial aggregates in dual-species cultures.

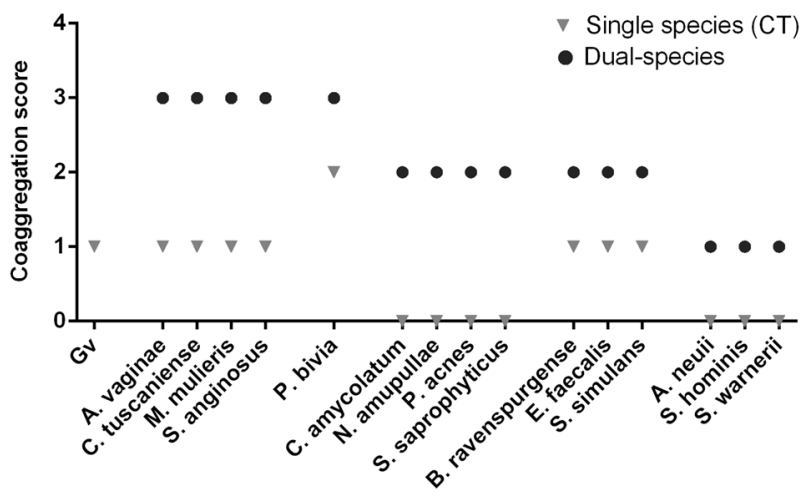

Fig. 1 Coaggregation score of mono- or dual- bacterial species. Coaggregation score was evaluated as following: 0 , no aggregation; 1 , small aggregates comprising small visible clusters of bacteria; 2, aggregates comprising larger numbers of bacteria, settling to the center of the well; 3, macroscopically visible clumps comprising larger groups of bacteria which settle to the center of the well; 4, maximum score allocated to describe a large, macroscopically visible clump in the center of the well. Auto-aggregation was assessed for each bacterial species, corresponding to the experimental control (CT). Each data point represents the mode

\section{In vitro PNA Gard162 probe specificity}

Despite the PNA Gard162 probe specificity having been previously tested for $22 \mathrm{G}$. vaginalis strains and for 27 other bacterial species commonly found in BV-associated microflora [47], here we also analyzed the probe specificity for the bacterial species that were not previously determined.Thus, we carried out an experiment in order to detect any possible cross-hybridization with any of the BVassociated species used herein (Supplementary Table S1). Based on these results, the Gard162 probe hybridized with a G. vaginalis strain, whereas no hybridization was observed for the other species tested, showing a specificity of $100 \%$ as previously reported [47].

\section{Quantification of bacterial populations in dual- species biofilms by PNA FISH}

Taking advantage of the robustness of the PNA FISH/ DAPI method (Supplementary Figure S1) for the differentiation between $G$. vaginalis and other BV-associated species, we discriminated the bacterial populations into dual-species BV-associated biofilms. Initially, we assessed the total cell number in each consortium by DAPI staining. Our results demonstrated that all tested dualspecies biofilms showed a considerable enhancement of the total number of cells, as compared with mono-species BVGv biofilms (Fig. 2a). However, under our in vitro conditions, we showed that most of the dual-species biofilms had slightly higher concentrations of the second $\mathrm{BV}$-associated species (Fig. 2b), in contrast to previous in vivo FISH observations [6, 29]. The only exceptions were when $A$. vaginae, $C$. amycolatum, $P$. bivia, or M. mulieris were added onto a pre-established BVGv biofilm.

\section{Analysis of dual-species biofilms by scanning and confocal microscopy}

The combined use of FISH with CLSM has been a useful tool to provide a better understanding of the distribution of bacterial population within the multispecies biofilms $[53,54]$. Thus, in order to visualize the spatial distribution and different architectures of the tested dual-species biofilms, we analyzed different z-stacks among the 15 bacterial consortia by FISH/CLSM. As shown in Fig. 3, we were able to conclude that a second-BV species could differentially associate with a pre-established $G$. vaginalis biofilm. We grouped the bacterial consortia with an apparent similar spatial arrangement in the dual-species biofilm, using three criteria for bacterial distribution: presence in the top (T); and bottom (B); layers of the biofilm, as well as the relative distribution and 
Fig. 2 Biofilm formation profiles for each BV-associated species consortium $\left(10^{7} \mathrm{CFU} / \mathrm{mL}\right.$ of $\mathrm{BVGv}$ and $10^{7} \mathrm{CFU} / \mathrm{mL}$ of BVassociated bacteria) on dualspecies biofilms. a Total cells counts by DAPI for mono- ( $G$. vaginalis controls) and dualspecies biofilms. b Total percentage of cells detected by PNA FISH for $48 \mathrm{~h}$ biofilms. Each data point represents the mean \pm s.d.. $*, \dagger$ Values are significantly different between the dual-species consortium and the mono-species $G$. vaginalis biofilm for 24 and $48 \mathrm{~h}$, respectively (independent samples $t$-test, $P<0.05$ for a). * Values are significantly different between the bacterial populations of $G$. vaginalis and second $\mathrm{BV}$-associated in dualspecies biofilms (paired samples $t$-test for $\mathbf{b}, P<0.05$ ) a

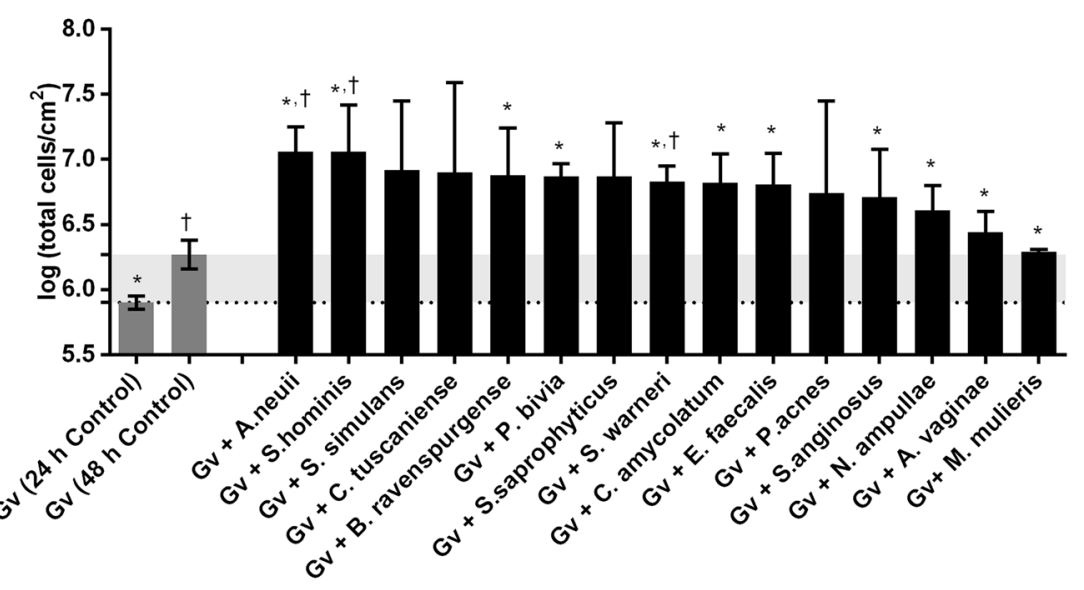

b

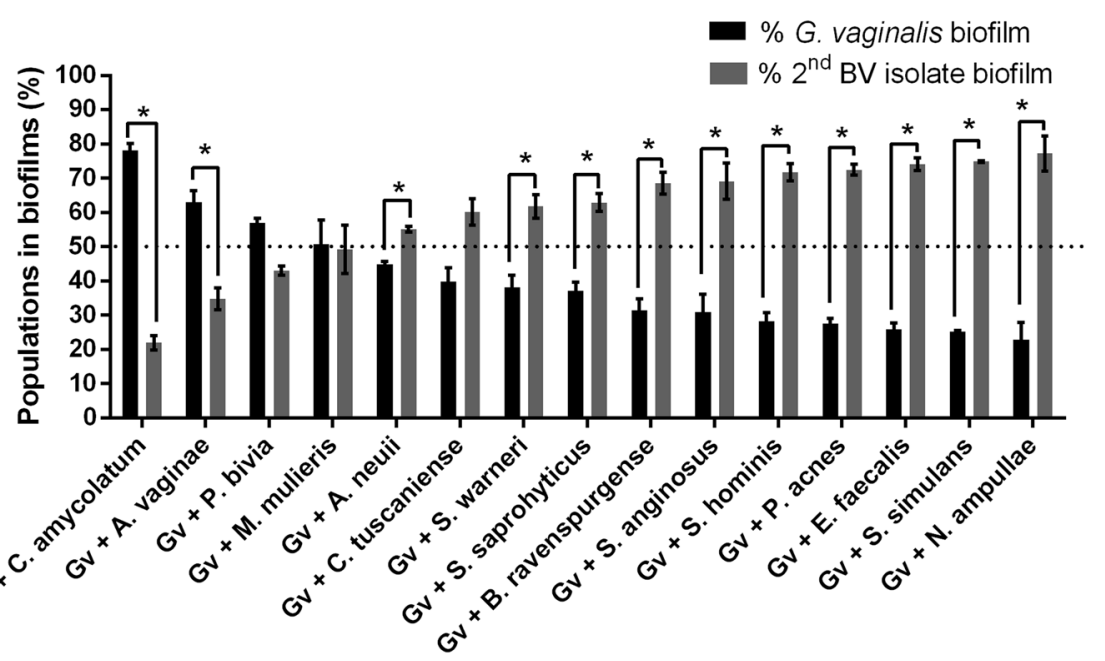

aggregation within the biofilm (D). For each criterion, we found two main phenotypes, as represented in schematic Fig. 4.

Taken together, these observations indicate that only in $27 \%$ of the tested bacterial consortia, the biofilm bottom was predominantly composed of $\mathrm{BVGv}$, with rare spots of second BV-associated bacteria (see B1 in Fig. 4). Otherwise, we noted that in the majority of the consortia, the secondary $\mathrm{BV}$-associated species were able to incorporate the lower layers of this in vitro dual-species preformed BVGv biofilm (see B2 in Fig. 4). Conversely, in $33 \%$ of the consortia, BVGv was absent in the top layers of the biofilm (see T2 in Fig. 4), whereas in the remaining cases a reduced concentration was observed going from the bottom to the top of the biofilm (see T1 in Fig. 4). Interestingly, from the bottom to the top layer of the biofilm, we observed that the majority of bacterial consortia $(80 \%)$ were not well distributed in a typical coaggregation structure $[55,56]$ (see D2 in Fig. 4), but were rather characterized by separate spatial clusters of
G. vaginalis (see D1 in Fig. 4), leading to the incorporation of $\mathrm{BV}$-associated bacteria in low numbers.

\section{Expression of critical genes related with G. vaginalis virulence can be altered in dual-species biofilms}

Changes in $G$. vaginalis transcriptome during the establishment of polymicrobial BV biofilms could be a key for unraveling whether the inter-species interplay enhances the virulence of $G$. vaginalis. Thus, to decipher the impact of the second-BV species on G. vaginalis pathogenicity, we analyzed the expression of genes related to cytotoxicity, biofilm formation, antimicrobial resistance, and evasion of the immune system [37], in cells from mono- and dualspecies biofilms.

$G$. vaginalis produces the toxin vaginolysin (vly), which might induce lysis in vaginal cells membranes [57]. Notably, our results indicated that in dual-species biofilms, the expression levels of $v l y$ were greatly up-regulated when $G$. vaginalis was associated with $A$. neuii or E. faecalis $(P<$ 


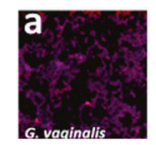

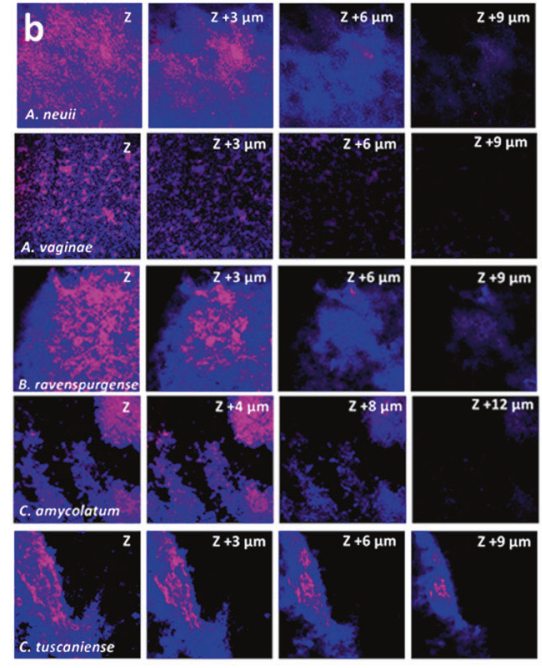

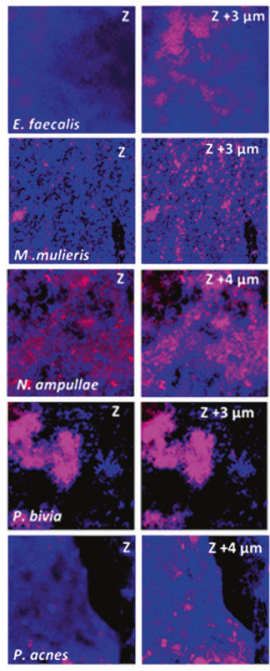

Fig. 3 An example data set on the organization of the dual-species BVassociated biofilm for $48 \mathrm{~h}$ by confocal laser scanning microscopy (CLSM). a G. vaginalis mono-species biofilm labeled with PNA-probe Gard162 and DAPI staining corresponding to an experimental control.

0.05; Fig. 5a). Furthermore, most of the other tested species also induced a slight increase in vly expression, B. ravenspurgense being the only species that repressed $G$. vaginalis $v l y$ expression. Regarding sialidase (sld), which facilitates the destruction of the protective mucus layer on the vaginal epithelium [58], E. faecalis, B. ravenspurgense, or A. neuii considerably up-regulated its expression on BVGv. Conversely, $S$. anginosus caused a statistically significant $(P<$ 0.05 ) reduction of sld expression (Fig. 5b).

It has been proposed that glycosyltransferases are likely to be important for the biosynthesis of exopolysaccharide, which in turn is important for the biofilm formation required for the full virulence of G. vaginalis [37, 59]. Not surprisingly, the expression of HMPREF0424_0821 transcript, which encodes glycosyltransferases type II, was upregulated in all consortia, with statistical significance in $73 \%$ of the tested dual-species biofilms (Fig. 5c). Nevertheless, further studies are required to clarify whether the overexpression of this transcript by BVGv could be caused by an enhancement of exopolysaccharide production or by a metabolic shift that could occur in the presence of secondary BV-associated species.

We also tested the expression of transcripts encoding antimicrobial-specific resistance proteins belonging to efflux pump families (HMPREF0424_1122 and HMPREF0424_0156), since it has been proposed that dual-species biofilms may confer antibiotic tolerance and resistance to mucosal immune defences [60]. Herein, the biggest difference found on the G. vaginalis
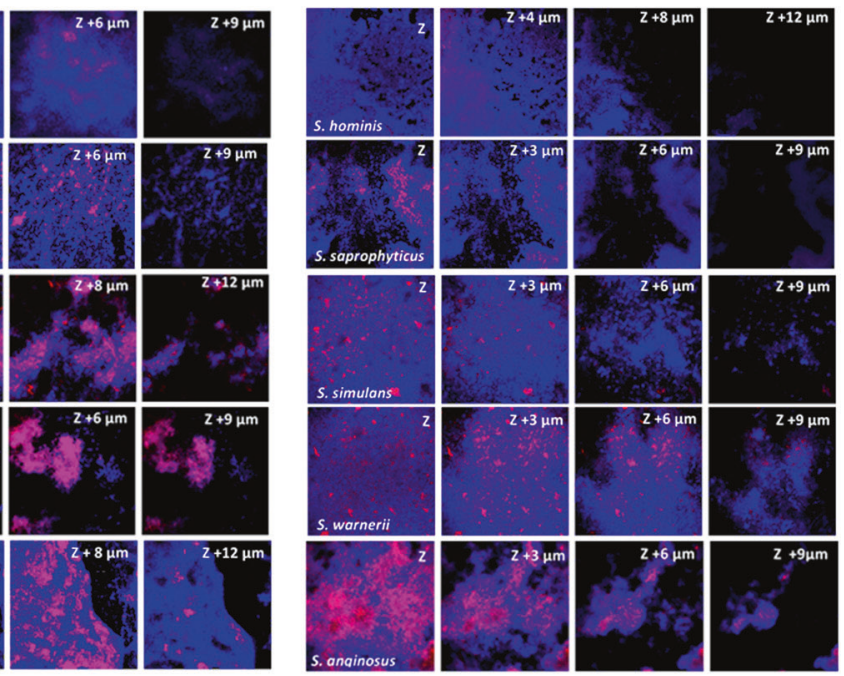

b CLSM images of dual-species biofilms for all 15 bacterial consortia. Images were acquired with $512 \times 512$ resolutions at four different regions of each surface analyzed

transcriptomic profile was caused by E. faecalis, in which we observed, on average, an expression of approx. 12-fold higher in the dual-species biofilms than in the mono-species biofilms $(P<0.05$; Fig. 5d, e). Contrariwise, only $S$. anginosus promoted a significantly $(P<0.05)$ reduction of the of transcription levels of HMPREF0424_0156 gene (Fig. 5e).

Finally, we analyzed the expression of HMPREF0424_1196 transcript, which encodes a Ribprotein that belongs to the $\alpha$-like protein (Alp)-family of highly repetitive surface antigens [61]. These proteins elicit protective immunity through their interstrain size variability [59]. Importantly, it was found that HMPREF0424_1196 transcript levels were greatly elevated $(P<0.05)$ when $E$. faecalis or $S$. warneii was cocultured with the BVGv pre-established biofilm (Fig. 5f). It is also worthwhile noting that the remaining BVassociated bacteria incited a more slight alteration in the transcription levels of HMPREF0424_1196 gene by BVGv biofilm cells.

\section{Discussion}

Microbial cell-cell interactions in the vaginal flora are believed to play an integral role in the development of biofilms and, ultimately, they can also generate an array of serious gynecological and obstetric complications [3, 62, 63]. The description of a polymicrobial biofilm 

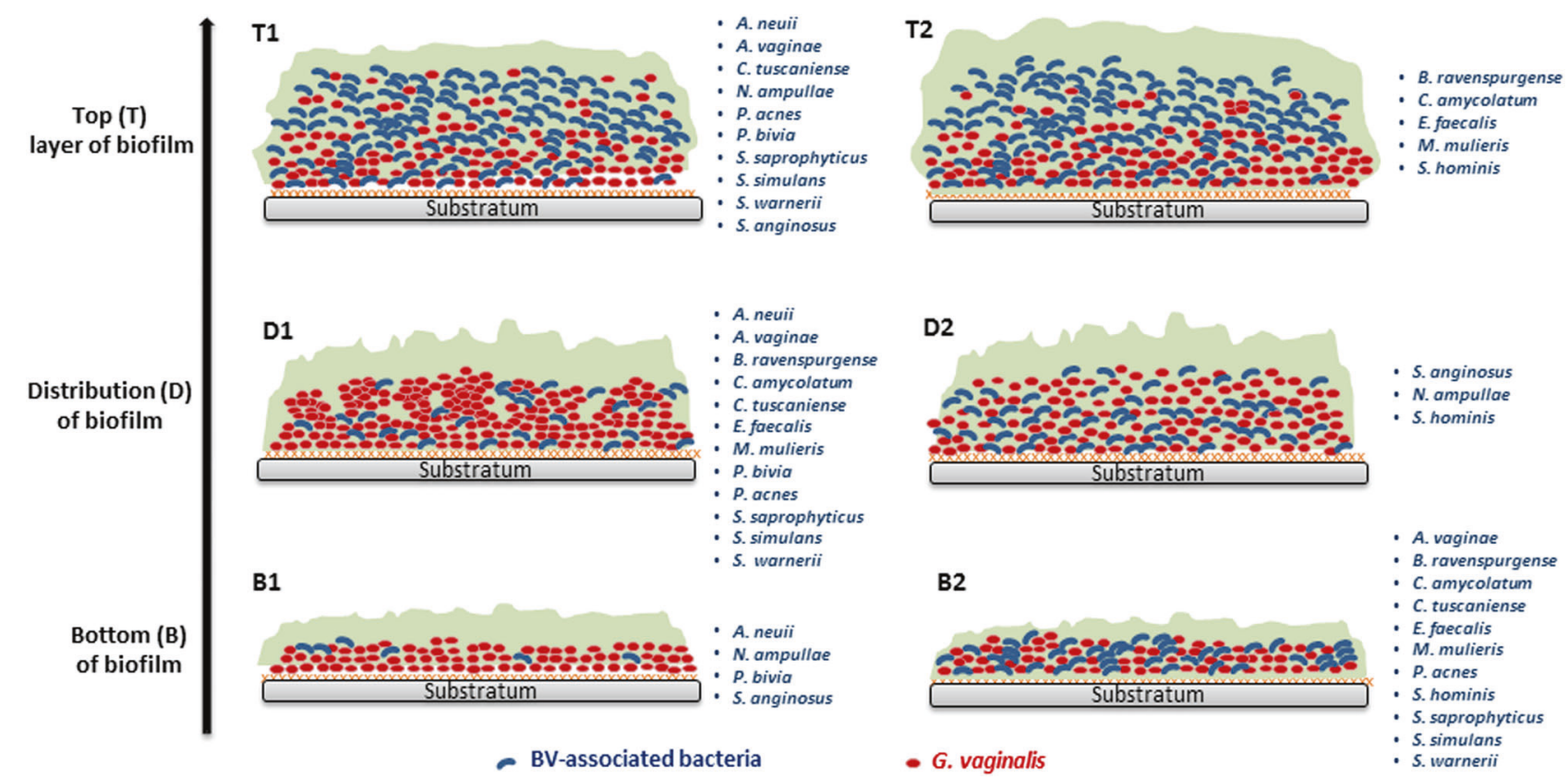

Fig. 4 Schematic representation of the distribution of dual-species BVassociated biofilm structure from the bottom to the biofilm top. (Bottom 1-B1) Predominantly G. vaginalis with rare spots of second BVisolate in the bottom; (Bottom 2-B2) both species in the bottom;

(Distribution 1-D1) G. vaginalis exists on clusters in the biofilm; (Distribution 2-D2) G. vaginalis is well distributed in the biofilm; (Top 1-T1) G. vaginalis is reduced from the bottom to the top; (Top 2-T2) G. vaginalis is absence on the top layer of biofilm

on the epithelial surface from BV vaginal biopsy specimens puts G. vaginalis, the major component of these multispecies communities, at the center of BV pathogenesis $[6,27,29,45,58]$. However, the effects of other species found in $\mathrm{BV}$-associated microflora on biofilm formation and its impact in $G$. vaginalis pathogenicity, the presumably primary etiologic agent of $\mathrm{BV}$, are still poorly known $[21,27,33,36]$. Importantly, we have previously shown that, by themselves, some BV-associated species lack key virulent traits [23]. Therefore, herein, we hypothesized that some, but not all, BV-associated species could enhance BVGv biofilms mediated virulence. We selected $15 \mathrm{BV}$ associated species previously characterized [23, 33] and assessed their interactions with BVGv using a dual-species biofilm model.

As we have demonstrated before, most of the tested BVsecondary species were able to enhance the total biomass of pre-established G. vaginalis biofilms [33]. Curiously, contrary to what has been described in vivo [6, 29, 64], most of our dual-species biofilms comprised slightly less than $50 \%$ of $G$. vaginalis. Discrepancies from in vitro and in vivo biofilms have been previously reported in other infections [65] and can be attributed to several factors. First, biofilm formation by $G$. vaginalis was pre-formed in tissue culture plates rather than on vaginal epithelium, where the presence of host-derived factors (e.g. mucus production, specific receptors on the epithelial surface) can influence the biofilm development. Unfortunately, this technical limitation is not easy to overcome since, as shown before, G. vaginalis

quickly induces cytotoxic changes and detachment of preadhered epithelial cultures [13, 14, 22]. Furthermore, the different optimal conditions of bacterial growth can lead to discrepant bacterial growth rates [66], and consequently directly impact the composition and possible bacterial interactions within the in vitro BV biofilms. To minimize this, we repeated the co-incubation experiments, using a lower bacterial concentration in order to mimic the vaginal microflora [67], but the overall results did not change significantly (Supplementary Figure S2).

In an effort to better understand the ecological interactions between BVGv and other BV-associated species, we also analyzed the architecture and bacterial spatial organization of in vitro BV biofilms, since this remains unclear. It has been shown before that microorganisms are not randomly organized within a multispecies biofilm, but follow a pattern that contributes to the fitness of the whole community [68, 69], for example, bacteria are organized in layers, clusters, or are well-mixed [70]. This spatial organization partially determines bacterial survival when the biofilm is exposed to toxic compounds [71]. This depends to a great extent on interactions between the species and their local micro-environments in the matrix with respect to nutrient, oxygen, and metabolite gradients [72]. To date, some studies have been shedding new light on the arrangement and spatial distribution of BV-associated biofilms through the analysis of vaginal specimens by using FISH [6, 27, 29, 31, 36, 64]. These studies have mainly focused on $G$. vaginalis and A. vaginae. It has been 
a

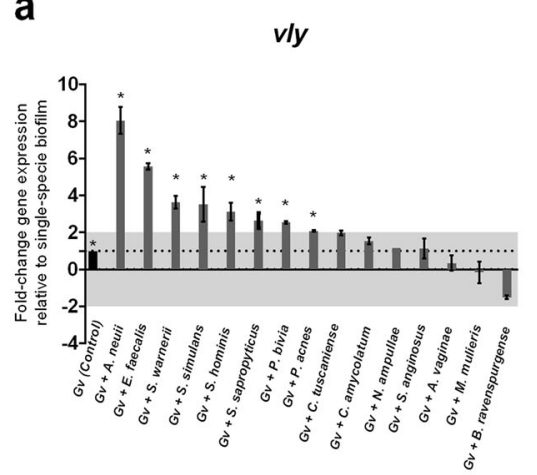

d

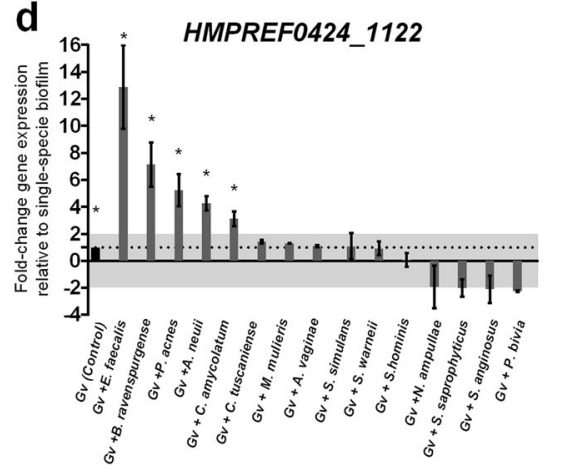

b

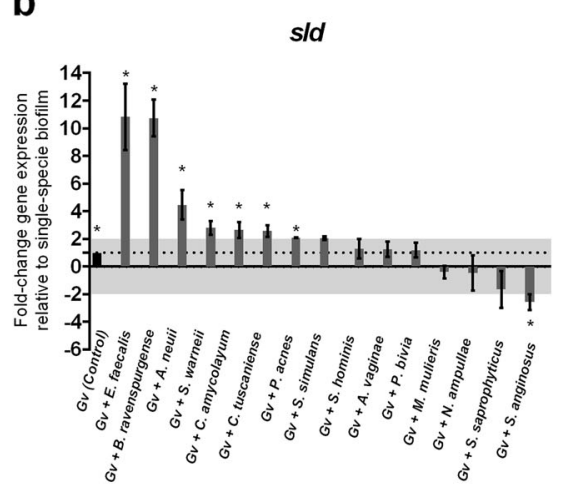

e

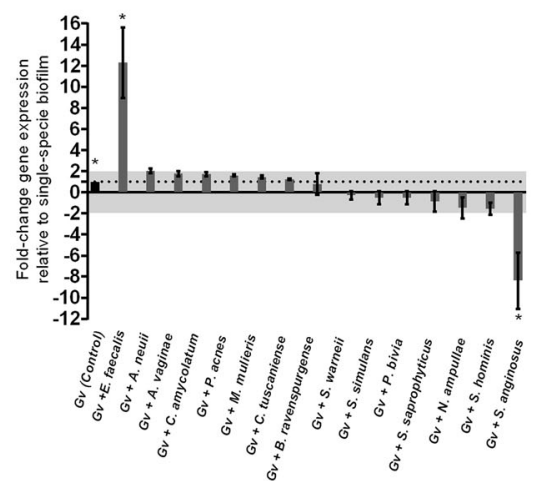

$\mathrm{C}_{100}$ * HMPREF0424_0821
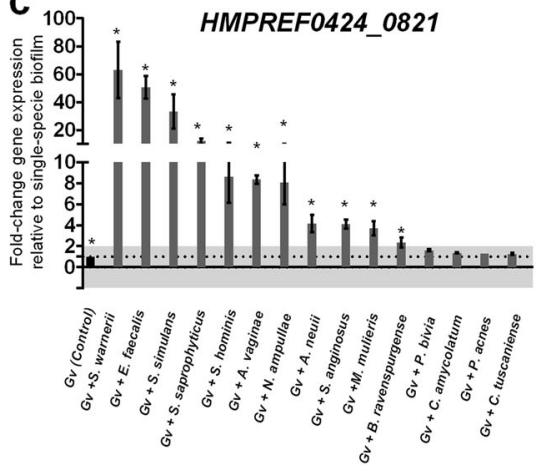

f

HMPREF0424_1196

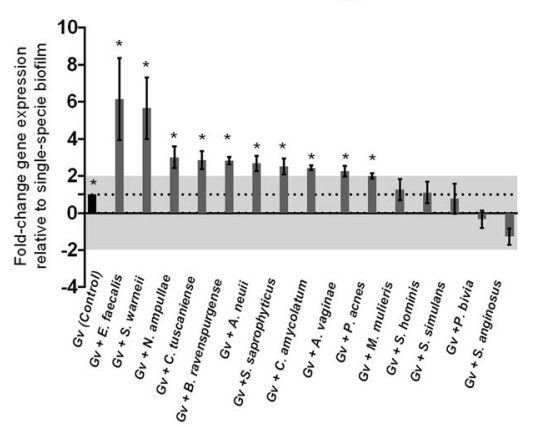

Fig. 5 Quantification of the transcription of known virulence genes in G. vaginalis cultured under dual- and mono-species biofilms. a Quantification of vaginolysin ( $v l y)$ transcription. b Quantification of sialidase (sld) transcription. c Quantification of HMPREF0424_0821 transcript, which encodes type II glycosyl-transferase. d Quantification of HMPREF0424_1122 transcript, which encodes a multidrug ABC transporter. e Quantification of HMPREF0424_0156 transcript, which encodes Bacitracin transport, ATP-binding protein BcrA.

proposed that the vaginal biofilm creates a favorable environment for anaerobic bacteria, due to the presence of an oxygen gradient within the biofilm. By embedding itself within the biofilm, A. vaginae can take advantage of the anaerobicity, proliferates, and exists in a mutualistic relationship with G. vaginalis. Remarkably, our present study provides new insights into the spatial distribution of multiple dual-species biofilms, since we found striking differences in the different consortia, suggesting that the type of bacterial interaction is species-specific in the presence of a polymicrobial community. Interestingly, the most predominant dual-species biofilm phenotype was characterized by the presence of both species on the biofilm bottom, with BVGv present in clusters in the intermediate layers, with higher concentration in the lower biofilm layers. This $G$. vaginalis spatial distribution in mixed biofilms could reflect a protective mode for $G$. vaginalis maintenance in adverse conditions, such as in the presence of antimicrobial compounds [73]. f Quantification of HMPREF0424_1196 transcript, which encodes a Rib-protein. The data indicate the fold-change expression of genes in $G$. vaginalis dual-species compared to mono-species $G$. vaginalis biofilm cells. For qPCR experiments, the bars represent the mean and the error bars the standard error of the mean (mean \pm s.e.m.). * Values are significantly different between the dual-species consortium and the mono-species G. vaginalis biofilm under the same conditions (nonparametric Mann-Whitney $U, P<0.05$ )

It is noteworthy that bacterial biofilms may also suppress certain virulence factors while others are activated in order to evade immune defenses and survive challenging conditions [74]. Therefore, we also analyzed how the different consortia could influence key virulence genes of G. vaginalis [13, 24, 37, 58, 59]. Several studies have highlighted the role of the vly gene in G. vaginalis virulence $[12,57,75-77]$. The $v l y$ gene belongs to the cholesteroldependent cytolysins (CDCs), a family of pore-forming toxins, which cause cytotoxicity on vaginal epithelium [57]. Interestingly, we recently showed that $v l y$ expression can vary according to $G$. vaginalis phenotype, in which we found higher $v l y$ transcript levels in a planktonic form than in mono-BVGv biofilm cells [37]. The lower levels of expression of $v l y$ transcript in single biofilms might reflect the more chronic nature of vaginal colonization by BVGv and serve as a means towards preventing a host immune response. Importantly, based on our present study, we also propose that under specific ecological conditions, some BV- 
a

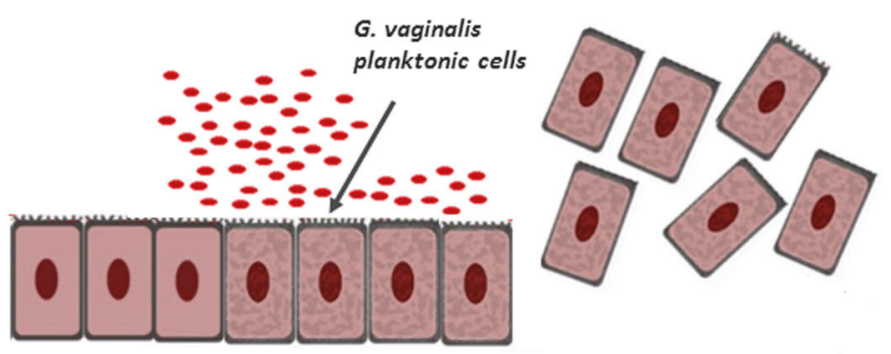

b

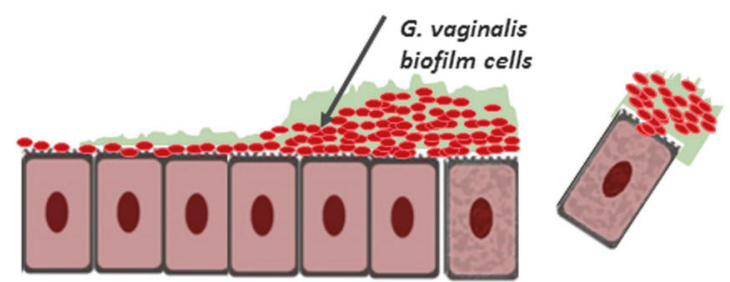

C

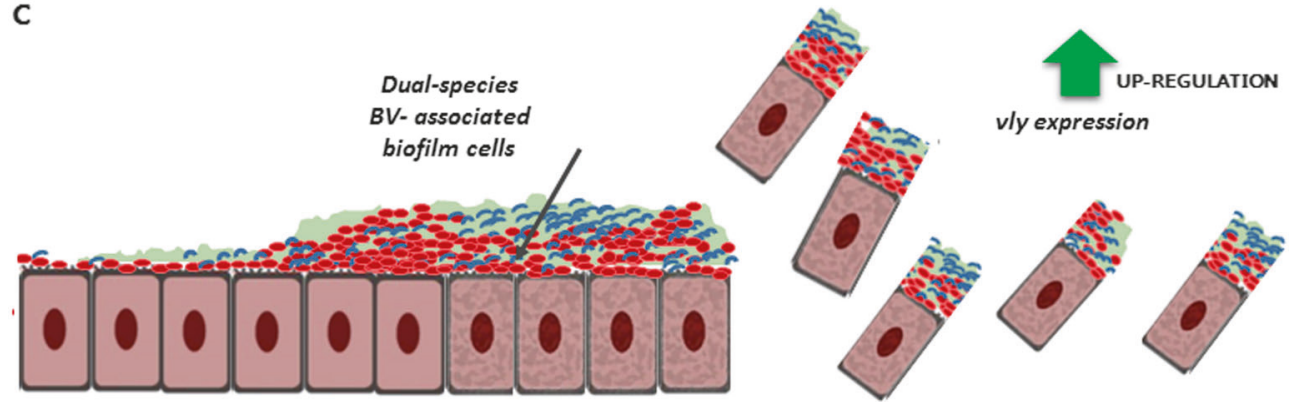

Fig. 6 Hypothetical model of G. vaginalis vaginolysin (vly)-mediated cytotoxicity in different bacterial phenotypes a planktonic cells, b $G$. vaginalis mono-species biofilm, $\mathbf{c}$ dual-species biofilms, corresponding

associated bacteria, in particular A. neuii or E. faecalis, can trigger an overexpression of $v l y$ transcript by BVGv cells. Consequently, the complex interplay between BVGv and specific BV-associated species can enhance vaginal desquamation and eventual formation of clue cells (Fig. 6).

The same trend was observed with sld, which is known to facilitate the destruction of the protective mucus layer on the vaginal epithelium by hydrolysis of sialic acid on the glycans of mucous membranes. This process possibly facilitates adhesion of bacteria on the vaginal epithelium since it has been linked with the development of biofilm [58]. Moreover, the biofilm formation was also likely to be affected by the glycosyltransferases type II [59]. Furthermore, similar to what was described in other mixed biofilm studies $[60,78]$, in the present study we also observed that some second $\mathrm{BV}$-associated species might likely confer an increase in antibiotic tolerance and resistance to mucosal immune defenses, thereby contributing to the persistence and recurrence of BV. to a pre-formed $\mathrm{BVGv}$ biofilm in association with a second $\mathrm{BV}$ associated bacteria

Taken together, this study reveals that molecular interactions were very specific to each consortium, confirming our original hypothesis that not all $\mathrm{BV}$-secondary bacteria contribute to the enhancement of $\mathrm{BV}$ pathogenesis by influencing G. vaginalis virulence. Interestingly, E. faecalis and $A$. neuii influenced more of the tested genes than other more commonly BV-associated species, such as $M$. mulieris or A. vaginae (Supplementary Figure S3). What this translates is that the mere presence of a specific bacterial species during BV does not imply that it has an active role during $\mathrm{BV}$ development, as previously proposed $[7,79]$. While $E$. faecalis is less often found in $\mathrm{BV}$, this is a known virulent species, which has also been isolated from patients with urinary tract infections [80] and vaginitis [81-83], whereas A. neuii can be isolated from a variety of infections [84], including genitourinary infections $[85,86]$. Both bacterial species have different factors implicated in the pathogenesis $[83,87]$, which may contribute to aggravate the outcomes, sequelae, and recurrence of BV. In any case, more basic 
research is needed to fully understand the pathways and functions of these potential virulence genes [88].

Overall, the evidence from this study points towards the idea that "social networking" between co-infecting bacteria can profoundly affect the progress of BV and its clinical outcome. Therefore, more research is needed to provide a better mechanistic insight into the complex interplay between $G$. vaginalis, the very wide range of BV-associated species, and their eukaryotic hosts. Understanding the molecular basis and biological effect of these inter-bacterial processes may provide novel information necessary to define new targets and strategies for BV control.

Acknowledgements This study was supported by the Portuguese Foundation for Science and Technology (FCT) by the funded project PTDC/BIA-MIC/28271/2017, under the scope of COMPETE 2020 (POCI-01-0145-FEDER-028271) and by the strategic funding of unit UID/BIO/04469/2013. The funders had no role in study design, data collection and analysis, decision to publish, or preparation of the manuscript. JC had an individual FCT fellowship (SFRH/ $\mathrm{BD} / 93963 / 2013)$. NC is an Investigador FCT. This manuscript was edited by American Manuscript Editors (https://www.americanma nuscripteditors.com).

\section{Compliance with ethical standards}

Conflict of interest The authors declare that they have no conflict of interest.

Publisher's note: Springer Nature remains neutral with regard to jurisdictional claims in published maps and institutional affiliations.

Open Access This article is licensed under a Creative Commons Attribution 4.0 International License, which permits use, sharing, adaptation, distribution and reproduction in any medium or format, as long as you give appropriate credit to the original author(s) and the source, provide a link to the Creative Commons license, and indicate if changes were made. The images or other third party material in this article are included in the article's Creative Commons license, unless indicated otherwise in a credit line to the material. If material is not included in the article's Creative Commons license and your intended use is not permitted by statutory regulation or exceeds the permitted use, you will need to obtain permission directly from the copyright holder. To view a copy of this license, visit http://creativecommons. org/licenses/by/4.0/.

\section{References}

1. Unemo M, Bradshaw CS, Hocking JS, de Vries HJC, Francis SC, Mabey D, et al. Sexually transmitted infections: challenges ahead. Lancet Infect Dis. 2017;17:e235-79.

2. Leitich H, Kiss H. Asymptomatic bacterial vaginosis and intermediate flora as risk factors for adverse pregnancy outcome. Best Pract Res Clin Obstet Gynaecol. 2007;21:375-90.

3. Mania-Pramanik J, Kerkar SC, Salvi VS. Bacterial vaginosis: a cause of infertility? Int J STD AIDS. 2009;20:778-81.

4. Ravel J, Brotman RM, Gajer P, Ma B, Nandy M, Fadrosh DW, et al. Daily temporal dynamics of vaginal microbiota before, during and after episodes of bacterial vaginosis. Microbiome. 2013;1:29.
5. Schwebke JR, Muzny CA, Josey WE. Role of Gardnerella vaginalis in the pathogenesis of bacterial vaginosis: a conceptual model. J Infect Dis. 2014;210:338-43.

6. Swidsinski A, Mendling W, Loening-Baucke V, Ladhoff A, Swidsinski S, Hale LP, et al. Adherent biofilms in bacterial vaginosis. Obstet Gynecol. 2005;106:1013-23.

7. Turovskiy Y, Sutyak Noll K, Chikindas ML. The aetiology of bacterial vaginosis. J Appl Microbiol. 2011;110:1105-28.

8. Zhou X, Brown CJ, Abdo Z, Davis CC, Hansmann MA, Joyce P, et al. Differences in the composition of vaginal microbial communities found in healthy Caucasian and black women. ISME J. 2007;1:121-33.

9. Chen X, Zhao X, Chen L, Zeng W, Xu H. Vaginitis caused by Corynebacterium amycolatum in a prepubescent girl. J Pediatr Adolesc Gynecol. 2015;28:e165-7.

10. Hardy L, Cerca N, Jespers V, Vaneechoutte M, Crucitti T. Bacterial biofilms in the vagina. Res Microbiol. 2017a;168:865-74.

11. Jung HS, Ehlers MM, Lombaard H, Redelinghuys MJ, Kock MM. Etiology of bacterial vaginosis and polymicrobial biofilm formation. Crit Rev Microbiol. 2017;43:651-67.

12. Abdelmaksoud AA, Girerd PH, Garcia EM, Brooks JP, Leftwich LM, Sheth NU, et al. Association between statin use, the vaginal microbiome, and Gardnerella vaginalis vaginolysin-mediated cytotoxicity. PloS ONE. 2017;12:e0183765.

13. Castro J, Alves P, Sousa C, Cereija T, Franca A, Jefferson KK, et al. Using an in-vitro biofilm model to assess the virulence potential of bacterial vaginosis or non-bacterial vaginosis Gardnerella vaginalis isolates. Sci Rep. 2015;5:11640.

14. Harwich M, Alves J, Buck G, Strauss J, Patterson J, Oki A, et al. Drawing the line between commensal and pathogenic Gardnerella vaginalis through genome analysis and virulence studies. BMC Genomics. 2010;11:375.

15. Hilbert DW, Schuyler JA, Adelson ME, Mordechai E, Sobel JD, Gygax SE. Gardnerella vaginalis population dynamics in bacterial vaginosis. Eur J Clin Microbiol Infect Dis. 2017;36: 1269-78.

16. Gardner HL, Dukes CD. Haemophilus vaginalis vaginitis: a newly defined specific infection previously classified non-specific vaginitis. Am J Obstet Gynecol. 1955;69:962-76.

17. Devillard E, Burton JP, Reid G. Complexity of vaginal microflora as analyzed by PCR denaturing gradient gel electrophoresis in a patient with recurrent bacterial vaginosis. Infect Dis Obstet Gynecol. 2005;13:25-31.

18. Menard JP, Fenollar F, Henry M, Bretelle F, Raoult D. Molecular quantification of Gardnerella vaginalis and Atopobium vaginae loads to predict bacterial vaginosis. Clin Infect Dis. 2008;47:3343.

19. Balashov SV, Mordechai E, Adelson ME, Gygax SE. Identification, quantification and subtyping of Gardnerella vaginalis in noncultured clinical vaginal samples by quantitative PCR. J Med Microbiol. 2014;63:162-75.

20. Hickey RJ, Forney LJ. Gardnerella vaginalis does not always cause bacterial vaginosis. J Infect Dis. 2014;15:1682-3.

21. Machado A, Jefferson KK, Cerca N. Interactions between Lactobacillus crispatus and bacterial vaginosis (BV)-associated bacterial species in initial attachment and biofilm formation. Int $\mathrm{J}$ Mol Sci. 2013b;14:12004-12.

22. Patterson JL, Stull-Lane A, Girerd PH, Jefferson KK. Analysis of adherence, biofilm formation and cytotoxicity suggests a greater virulence potential of Gardnerella vaginalis relative to other bacterial-vaginosis-associated anaerobes. Microbiology. 2010; 156:392-9.

23. Alves P, Castro J, Sousa C, Cereija TB, Cerca N. Gardnerella vaginalis outcompetes 29 other bacterial species isolated from patients with bacterial vaginosis, using in an in vitro biofilm formation model. J Infect Dis. 2014;210:593-6. 
24. Ahmed A, Earl J, Retchless A, Hillier SL, Rabe LK, Cherpes TL, et al. Comparative genomic analyses of 17 clinical isolates of Gardnerella vaginalis provide evidence of multiple genetically isolated clades consistent with subspeciation into genovars. J Bacteriol. 2012;194:3922-37.

25. Janulaitiene M, Paliulyte V, Grinceviciene S, Zakareviciene J, Vladisauskiene A, Marcinkute A, et al. Prevalence and distribution of Gardnerella vaginalis subgroups in women with and without bacterial vaginosis. BMC Infect Dis. 2017;17:394.

26. Schellenberg JJ, Paramel Jayaprakash T, Withana Gamage N, Patterson MH, Vaneechoutte M, Hill JE. Gardnerella vaginalis subgroups defined bycpn60 sequencing and sialidase activity in isolates from Canada, Belgium and Kenya. PLoS ONE. 2016;11: $\mathrm{e} 0146510$.

27. Hardy L, Jespers V, Dahchour N, Mwambarangwe L, Musengamana V, Vaneechoutte $\mathrm{M}$, et al. Unravelling the bacterial vaginosis-associated biofilm: a multiplex Gardnerella vaginalis and Atopobium vaginae fluorescence in situ hybridization assay using peptide nucleic acid probes. PLoS ONE. 2015;10: e0136658.

28. Machado A, Cerca N. Influence of biofilm formation by Gardnerella vaginalis and other anaerobes on bacterial vaginosis. $\mathrm{J}$ Infect Dis. 2015;212:1856-61.

29. Swidsinski A, Loening-Baucke V, Mendling W, Dörffel Y, Schilling J, Halwani Z, et al. Infection through structured polymicrobial Gardnerella biofilms (StPM-GB). Histol Histopathol. 2013;29:567-87.

30. Marrazzo JM. Interpreting the epidemiology and natural history of bacterial vaginosis: are we still confused? Anaerobe. 2011;17: 186-90.

31. Swidsinski A, Mendling W, Loening-Baucke V, Swidsinski S, Dörffel Y, Scholze J, et al. An adherent Gardnerella vaginalis biofilm persists on the vaginal epithelium after standard therapy with oral metronidazole. Am J Obstet Gynecol. 2008;198:97. e91-6.

32. Bradshaw CS, Morton AN, Hocking J, Garland SM, Morris MB, Moss LM, et al. High recurrence rates of bacterial vaginosis over the course of 12 months after oral metronidazole therapy and factors associated with recurrence. J Infect Dis. 2006;193: 1478-86.

33. Castro J, Cerca N. BV and non-BV associated Gardnerella vaginalis establish similar synergistic interactions with other BVassociated microorganisms in dual-species biofilms. Anaerobe. 2015;36:56-9.

34. Castro J, Machado D, Cerca N. Escherichia coli and Enterococcus faecalis are able to incorporate and enhance a pre-formed Gardnerella vaginalis biofilm. Pathog Dis. 2016;74:ftw007.

35. Cox C, Watt AP, McKenna JP, Coyle PV. Mycoplasma hominis and Gardnerella vaginalis display a significant synergistic relationship in bacterial vaginosis. Eur J Clin Microbiol Infect Dis. 2016;35:481-7.

36. Hardy L, Jespers V, Abdellati S, De Baetselier I. A fruitful alliance: the synergy between Atopobium vaginae and Gardnerella vaginalis in bacterial vaginosis-associated biofilm. Sex Transm Infect. 2016;10:pii: sextrans-2015-052475.

37. Castro J, França A, Bradwell KR, Serrano MG, Jefferson KK, Cerca N. Comparative transcriptomic analysis of Gardnerella vaginalis biofilms $v s$. planktonic cultures using RNA-seq. npj Biofilms Microbes. 2017;3:3.

38. Wen ZT, Yates D, Ahn S-J, Burne RA. Biofilm formation and virulence expression by Streptococcus mutans are altered when grown in dual-species model. BMC Microbiol. 2010;10: 111-111.

39. Vandecandelaere I, Van Nieuwerburgh F, Deforce D, Coenye T. Metabolic activity, urease production, antibiotic resistance and virulence in dual species biofilms of Staphylococcus epidermidis and Staphylococcus aureus. PLoS ONE. 2017;12:e172700.

40. Luppens SB, Kara D, Bandounas L, Jonker MJ, Wittink FR, Bruning O, et al. Effect of Veillonella parvula on the antimicrobial resistance and gene expression of Streptococcus mutans grown in a dual-species biofilm. Oral Microbiol Immunol. 2008;23:183-9.

41. Lagier JC, Edouard S, Pagnier I, Mediannikov O, Drancourt M, Raoult D. Current and past strategies for bacterial culture in clinical microbiology. Clin Microbiol Rev. 2015;28:208-36.

42. Pybus V, Onderdonk AB. Evidence for a commensal, symbiotic relationship between Gardnerella vaginalis and Prevotella bivia involving ammonia: potential significance for bacterial vaginosis. J Infect Dis. 1997;175:406-13.

43. Onderdonk AB, Delaney ML, Fichorova RN. The human microbiome during bacterial vaginosis. Clin Microbiol Rev. 2016; 29:223-38.

44. Reid G, McGroarty JA, Domingue PG, Chow AW, Bruce AW, Eisen A, et al. Coaggregation of urogenital bacteria in vitro and in vivo. Curr Microbiol. 1990;20:47-52.

45. Verstraelen H, Swidsinski A. The biofilm in bacterial vaginosis: implications for epidemiology, diagnosis and treatment. Curr Opin Infect Dis. 2013;26:86-89.

46. Freitas AI, Vasconcelos C, Vilanova M, Cerca N. Optimization of an automatic counting system for the quantification of Staphylococcus epidermidis cells in biofilms. J Basic Microbiol. 2014;54:750-7.

47. Machado A, Almeida C, Salgueiro D, Henriques A, Vaneechoutte M, Haesebrouck F, et al. Fluorescence in situ hybridization method using peptide nucleic acid probes for rapid detection of Lactobacillus and Gardnerella spp. BMC Microbiol. 2013a; 13:82.

48. França A, Freitas AI, Henriques AF, Cerca N. Optimizing a qPCR gene expression quantification assay for $S$. epidermidis biofilms: a comparison between commercial kits and a customized protocol. PloS ONE. 2012;7:e37480.

49. Carvalhais V, Delgado-Rastrollo M, Melo LD, Cerca N. Controlled RNA contamination and degradation and its impact on qPCR gene expression in S. epidermidis biofilms. J Microbiol Methods. 2013;95:195-200.

50. Pfaffl MW. Quantification PCR In: A-Z of quantitative PCR. Bustin SA, editor. Series 5, Ch. 3. International University Line, La Jolla, CA, USA; 2004.

51. Peters BM, Jabra-Rizk MA, O'May GA, Costerton JW, Shirtliff ME. Polymicrobial interactions: impact on pathogenesis and human disease. Clin Microbiol Rev. 2012;25:193-13.

52. Reardon-Robinson ME, Wu C, Mishra A, Chang C, Bier N, Das $\mathrm{A}$, et al. Pilus hijacking by a bacterial coaggregation factor critical for oral biofilm development. Proc Natl Acad Sci USA. 2014; 111:3835-40.

53. Karygianni L, Follo M, Hellwig E, Burghardt D, Wolkewitz M, Anderson A, et al. Microscope-based imaging platform for largescale analysis of oral biofilms. Appl Environ Microbiol. 2012;78:8703-11.

54. Palmer RJ Jr., Sternberg C. Modern microscopy in biofilm research: confocal microscopy and other approaches. Curr Opin Biotechnol. 1999;10:263-8.

55. Katharios-Lanwermeyer S, Xi C, Jakubovics NS, Rickard AH. Mini-review: Microbial coaggregation: ubiquity and implications for biofilm development. Biofouling. 2014;30:1235-51.

56. Almstrand R, Daims H, Persson F, Sörensson F, Hermansson M. New methods for analysis of spatial distribution and coaggregation of microbial populations in complex biofilms. Appl Environ Microbiol. 2013;79:5978-5987.

57. Gelber SE, Aguilar JL, Lewis KL, Ratner AJ. Functional and phylogenetic characterization of Vaginolysin, the human-specific 
cytolysin from Gardnerella vaginalis. J Bacteriol. 2008;190:3896-3903.

58. Hardy L, Jespers V, Van den Bulck M, Buyze J, Mwambarangwe $\mathrm{L}$, Musengamana V, et al. The presence of the putative Gardnerella vaginalis sialidase A gene in vaginal specimens is associated with bacterial vaginosis biofilm. PLOS ONE. 2017;12: e0172522.

59. Yeoman CJ, Yildirim S, Thomas SM, Durkin AS, Torralba M, Sutton G, et al. Comparative genomics of Gardnerella vaginalis strains reveals substantial differences in metabolic and virulence potential. PLoS ONE. 2010;5:e12411.

60. Nair N, Biswas R, Götz F, Biswas L. Impact of Staphylococcus aureus on pathogenesis in polymicrobial infections. Infect Immun. 2014;82:2162-9.

61. Lindahl G, Stalhammar-Carlemalm M, Areschoug T. Surface proteins of Streptococcus agalactiae and related proteins in other bacterial pathogens. Clin Microbiol Rev. 2005;18:102-27.

62. Leitich H, Bodner-Adler B, Brunbauer M, Kaider A, Egarter C, Husslein P. Bacterial vaginosis as a risk factor for preterm delivery: a meta-analysis. Am J Obstet Gynecol. 2003;189:139-47.

63. Menard JP, Mazouni C, Salem-Cherif I, Fenollar F, Raoult D, Boubli $\mathrm{L}$, et al. High vaginal concentrations of Atopobium vaginae and Gardnerella vaginalis in women undergoing preterm labor. Obstet Gynecol. 2010;115:134-40.

64. Swidsinski A, Doerffel Y, Loening-Baucke V, Swidsinski S, Verstraelen H, Vaneechoutte M, et al. Gardnerella biofilm involves females and males and is transmitted sexually. Gynecol Obstet Invest. 2010;70:256-63.

65. Lebeaux D, Chauhan A, Rendueles O, Beloin C. From in vitro to in vivo models of bacterial biofilm-related infections. Pathogens. 2013;2:288-56.

66. Aldea M, Jenkins K, Csikász-Nagy A. Growth rate as a direct regulator of the start network to set cell size. Front Cell Dev Biol. 2017;5:57.

67. Xiao B, Niu X, Han N, Wang B, Du P, Na R, et al. Predictive value of the composition of the vaginal microbiota in bacterial vaginosis, a dynamic study to identify recurrence-related flora. Sci Rep. 2016;6:26674.

68. Marsh P, Bradshaw D. Dental plaque as a biofilm. J Ind Microbiol. 1995;15:169-75.

69. Rickard AH, Gilbert P, High NJ, Kolenbrander PE, Handley PS. Bacterial coaggregation: an integral process in the development of multi-species biofilms. Trends Microbiol. 2003;11:94-100.

70. Elias S, Banin E. Multi-species biofilms: living with friendly neighbors. FEMS Microbiol Rev. 2012;36:990-1004.

71. Simoes M, Simões LC, Vieira MJ. Species association increases biofilm resistance to chemical and mechanical treatments. Water Res. 2009;43:229-37.

72. Stewart PS, Franklin MJ. Physiological heterogeneity in biofilms. Nat Rev Microbiol. 2008;6:199-210.

73. Jefferson KK. What drives bacteria to produce a biofilm? FEMS Microbiol Lett. 2004;236:163-73.
74. Algburi A, Comito N, Kashtanov D, Dicks LM, Chikindas ML. Control of biofilm formation: antibiotics and beyond. Appl Environ Microbiol. 2017;83:pii: e02508-16.

75. Castro J, Martins AP, Rodrigues ME, Cerca N. Lactobacillus crispatus represses vaginolysin expression by BV associated Gardnerella vaginalis and reduces cell cytotoxicity. Anaerobe. 2018;50:60-63.

76. Cauci S, Monte R, Ropele M, Missero C, Not T, Quadrifoglio F, et al. Pore-forming and haemolytic properties of the Gardnerella vaginalis cytolysin. Mol Microbiol. 1993;9:1143-55.

77. Randis TM, Kulkarni R, Aguilar JL, Ratner AJ. Antibody-based detection and inhibition of vaginolysin, the Gardnerella vaginalis cytolysin. PLoS ONE. 2009;4:e5207.

78. Burmølle M, Webb JS, Rao D, Hansen LH, Sørensen SJ, Kjelleberg S. Enhanced biofilm formation and increased resistance to antimicrobial agents and bacterial invasion are caused by synergistic interactions in multispecies biofilms. Appl Environ Microbiol. 2006;72:3916-23.

79. Muzny CA, Schwebke JR. Pathogenesis of bacterial vaginosis: discussion of current hypotheses. J Infect Dis. 2016; 214:S1-5.

80. Kline KA, Lewis AL. Gram-positive uropathogens, polymicrobial urinary tract infection, and the emerging microbiota of the urinary tract. Microbiol Spectr. 2016; 4: https://doi.org/10.1128/ microbiolspec.UTI-0012-2012.

81. Fan A, Yue Y, Geng N, Zhang H, Wang Y, Xue F. Aerobic vaginitis and mixed infections: comparison of clinical and laboratory findings. Arch Gynecol Obstet. 2013;287:329-35.

82. Tansarli GS, Skalidis T, Legakis NJ, Falagas ME. Abnormal vaginal flora in symptomatic non-pregnant and pregnant women in a Greek hospital: a prospective study. Eur J Clin Microbiol Infect Dis. 2017;36:227-32.

83. Wong VK, Turmezei TD, Weston VC. Actinomycosis. BMJ. 2011;343:d6099.

84. Zelyas N, Gee S, Nilsson B, Bennett T, Rennie R. Infections caused by Actinomyces neuii: a case series and review of an unusual bacterium. Can J Infect Dis Med Microbiol. 2016; 2016:6017605.

85. Hall V, Talbot PR, Stubbs SL, Duerden BI. Identification of clinical isolates of Actinomyces species by amplified $16 \mathrm{~S}$ ribosomal DNA restriction analysis. J Clin Microbiol. 2001; 39:3555-62.

86. Mann C, Dertinger S, Hartmann G, Schurz R, Simma B. Actinomyces neuii and neonatal sepsis. Infection. 2002;30: 178-80.

87. Saffari F, Dalfardi MS, Mansouri S, Ahmadrajabi R. Survey for correlation between biofilm formation and virulence determinants in a collection of pathogenic and fecal Enterococcus faecalis isolates. Infect Chemother. 2017;49: 176-83.

88. Pundir S, Martin MJ, O’Donovan C. UniProt Tools. Curr Protoc Bioinformatics. 2016;53:1.29.21-29.15. 